Erratum

\title{
Erratum to "The Preventive Effect of Biochanin A on Bone Loss in Ovariectomized Rats: Involvement in Regulation of Growth and Activity of Osteoblasts and Osteoclasts"
}

\author{
Shu-Jem Su, Yao-Tsung Yeh, and Huey-Wen Shyu \\ Department of Medical Laboratory Science and Biotechnology, School of Medicine and Health Sciences, Fooyin University, \\ No. 151, Chinhsueh Road, Ta-liao, Kaohsiung 83101, Taiwan
}

Correspondence should be addressed to Shu-Jem Su; sc096@mail.fy.edu.tw

Received 10 March 2013; Accepted 21 March 2013

Copyright (C) 2013 Shu-Jem Su et al. This is an open access article distributed under the Creative Commons Attribution License, which permits unrestricted use, distribution, and reproduction in any medium, provided the original work is properly cited.

Since the publication of the original paper, the authors have noticed an error in the primer sequences. The correct primer sequences are as follows.

"Osterix (NM_001037632): forward: $5^{\prime}$-cccgtctgactttgccccc-3', reverse: $5^{\prime}$-ctgccccactgcctgcatat $3^{\prime}$ (203 bp); ALP (NM_013059): forward: $5^{\prime}$-tggacggtgaacgggagaac- $3^{\prime}$, reverse: $5^{\prime}$-cagagctggcccaggcaca- $3^{\prime}$ (238 bp); collagen type I (NM_053304):forward: $5^{\prime}$-agcctggacttcctggtcct- 3 ', reverse: $5^{\prime}$ gctcgccaggttcaccagg-3' (219 bp); Osteocalcin (NM_013414): forward: $5^{\prime}$-tgaggaccctctctctgctc- $3^{\prime}$, reverse: $5^{\prime}$-accaccttactgccctcctg- $3^{\prime}$ (130 bp); OPG (NM_012870): forward: $5^{\prime}$ tgacccagaaaccggacgtc- $3^{\prime}$, reverse: $5^{\prime}$-gttgcactcctgtttcacggt- $3^{\prime}$ (202 bp); RANKL (NM_057149): forward: $5^{\prime}$-g gctcggaggagatgggca- $3^{\prime}, \quad$ reverse: $5^{\prime}$-agcgccaggaacatgaagcg- $3^{\prime}$ (119 bp); and TRAP (NM_019144): forward: $5^{\prime}$-cacctgtgcttcctccagca$3^{\prime}$, reverse: $5^{\prime}$-gcccataatctgcacggttc- $3^{\prime}(151 \mathrm{bp})$. GAPDH (NM_017008): forward: $5^{\prime}$-cctgcaccac caactgctta- $3^{\prime}$, reverse: $5^{\prime}$-ggccatccacagtcttctgag- $3^{\prime}$ (140 bp)."

In PCR amplification, " $52^{\circ} \mathrm{C}$ for $1 \mathrm{~min}$ " should be corrected as " $64^{\circ} \mathrm{C}$ for 1 min."

In Figures 1 and 2, NADPH should be corrected to GAPDH, as shown here.

The authors apologize for this error and any inconvenience caused.

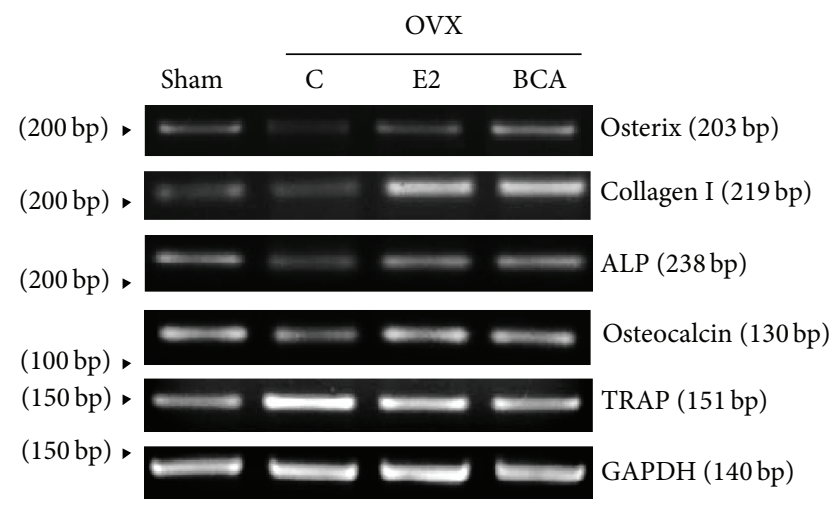

Figure 1

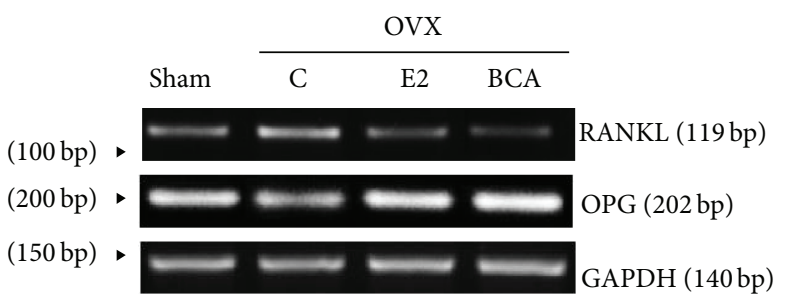

FiguRE 2 


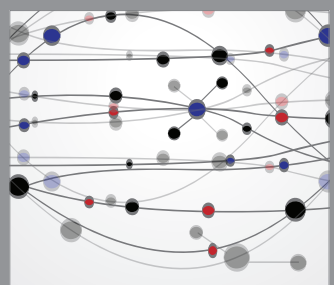

The Scientific World Journal
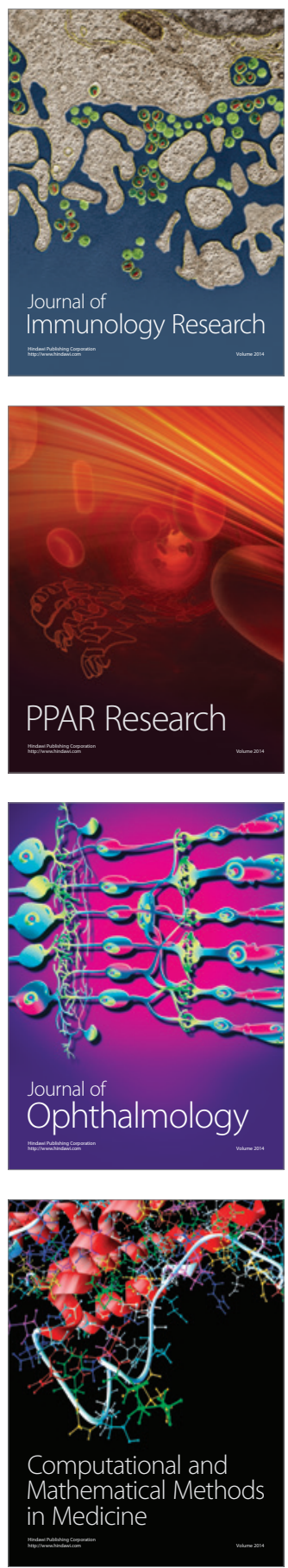

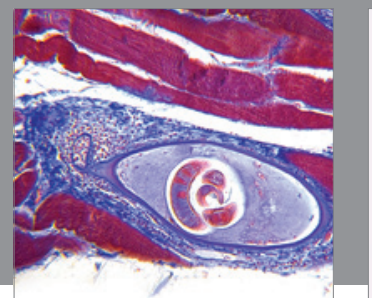

Gastroenterology

Research and Practice
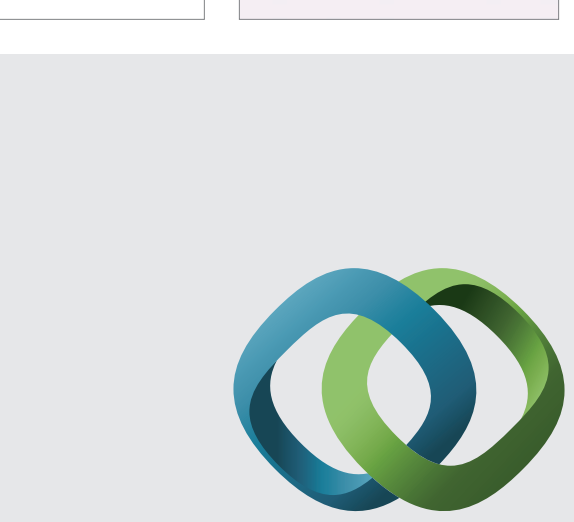

\section{Hindawi}

Submit your manuscripts at

http://www.hindawi.com
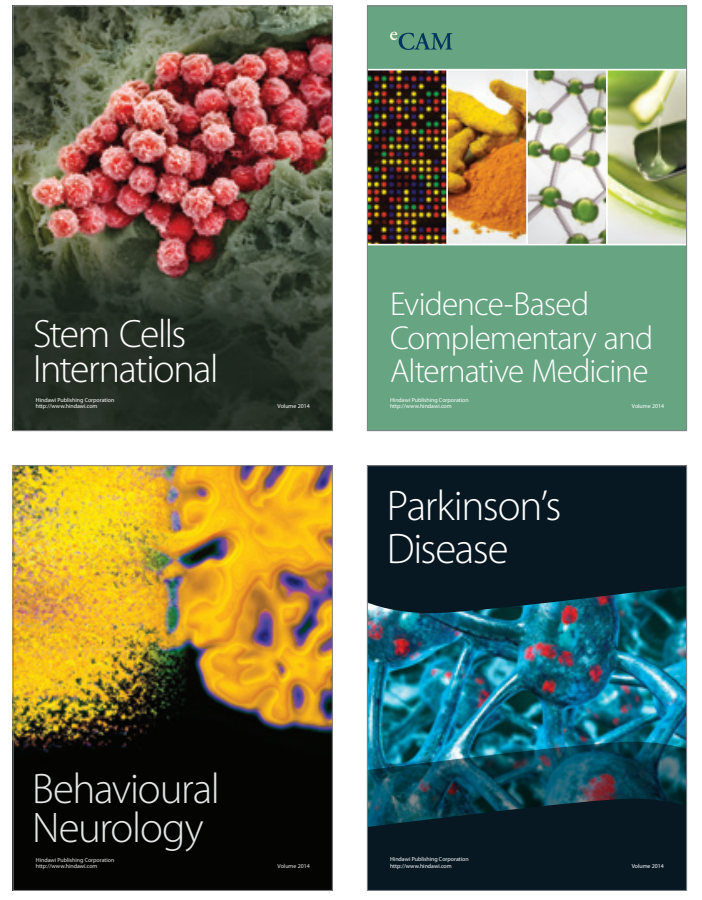
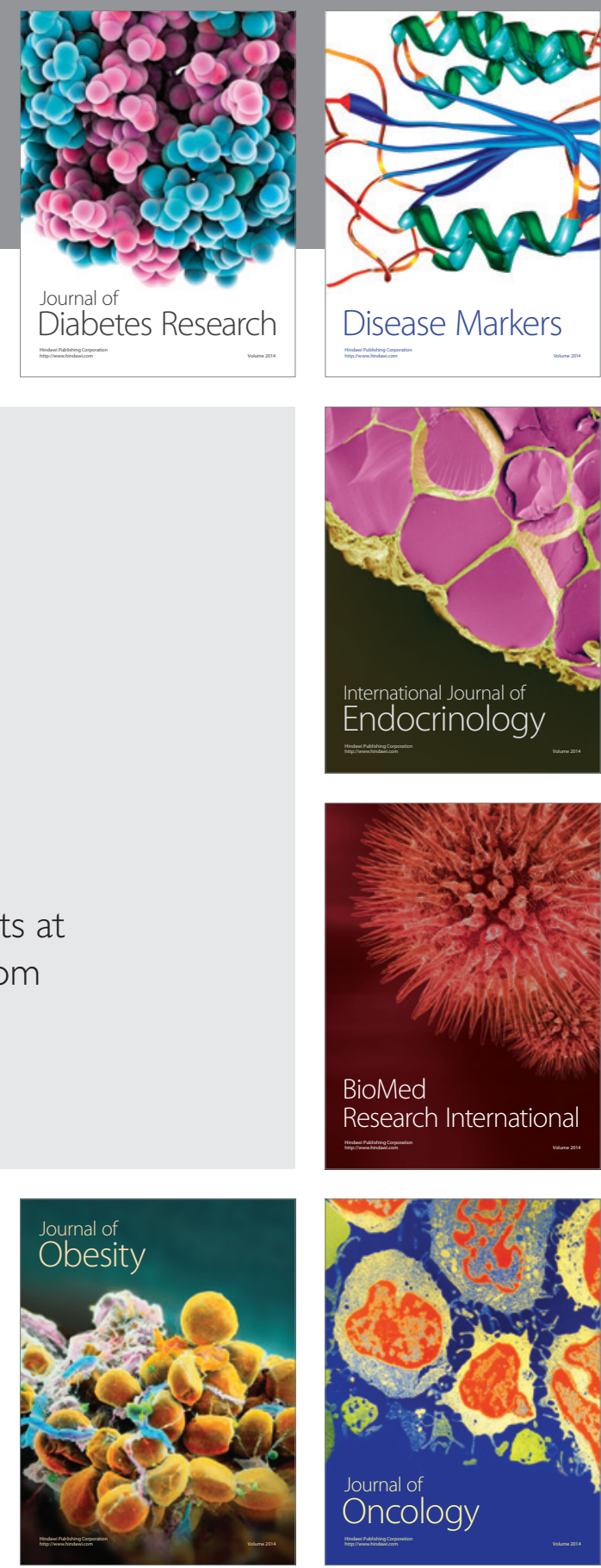

Disease Markers
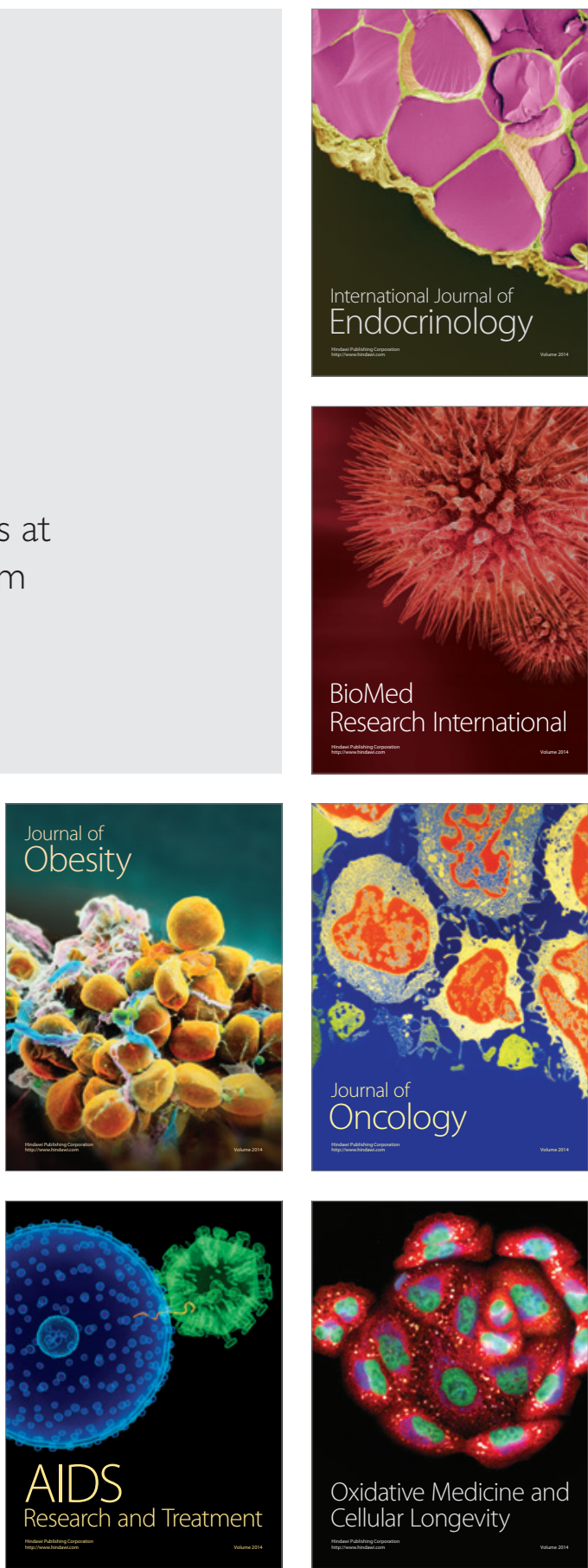